\title{
Analyzing the supply chain using SCOR model in a steel producing company
}

\author{
Mehdi Seifbarghy $^{1}$, Mohammad Reza Akbari² and Mohsen Ssheikh Sajadieh ${ }^{2}$ \\ ${ }^{1}$ Department of Industrial Engineering, Alzahra University, Tehran, Iran \\ ${ }^{2}$ Department of Industrial Engineering Sharif University of Technology Tehran, Iran
}

\begin{abstract}
Supply Chain Operations Reference (SCOR) model is developed and maintained by the Supply Chain Council (SCC). The model is a reference model which can be used to map, benchmark and improve the supply chain operations. SCOR model provides companies with a basic process modeling tool, an extensive benchmark database and defines a set of supply chain metrics. Mobarakeh Steel Company (located in Isfahan, Iran) initiated the project of studying and analyzing its supply chain performance based on the SCOR model. This paper explains the steps and the results of the project. Interviews with the managers and considering the documents on the four major subjects of planning, logistics, information flow and relationships in the supply chain and comparing the current conditions of the supply chain with SCOR best practices, some improvement projects were proposed to improve the supply chain performance. The projects were then prioritized based on the supply chain strategy and the predecessor relationships.
\end{abstract}

Keywords: Supply Chain, SCOR, TOPSIS, Steel industry. 